OPEN ACCESS

Edited by:

Kathryn Wood,

University of Oxford, UK

Reviewed by:

Stanislaw Stepkowski,

University of Toledo College of

Medicine, USA

Dennis O. Adeegbe,

Dana Farber Cancer Institute and

Harvard Medical School, USA

${ }^{*}$ Correspondence:

Takuya Ueno

ueno.takuya@mgh.harvard.edu

Specialty section:

This article was submitted to Alloimmunity and Transplantation,

a section of the journal

Frontiers in Immunology

Received: 04 December 2015 Accepted: 22 February 2016

Published: 09 March 2016

Citation:

Ito T, Yamada A, Batal I, Yeung MY, McGrath MM, Sayegh MH,

Chandraker A and Ueno T (2016) The

Limits of Linked Suppression for Regulatory T Cells.

Front. Immunol. 7:82.

doi: 10.3389/fimmu.2016.00082

\title{
The Limits of Linked Suppression for Regulatory T Cells
}

\section{Toshiro Ito $^{1}$, Akira Yamada ${ }^{1}$, Ibrahim Batal ${ }^{2}$, Melissa Y. Yeung ${ }^{2}$, Martina M. McGrath ${ }^{2}$, Mohamed $H$. Sayegh ${ }^{2}$, Anil Chandraker ${ }^{2}$ and Takuya Ueno ${ }^{1,2 *}$}

\footnotetext{
1 Transplantation Unit, Surgical Services, Massachusetts General Hospital, Harvard Medical School, Boston, MA, USA, ${ }^{2}$ Transplantation Research Center, Brigham and Women's Hospital and Children's Hospital, Harvard Medical School, Boston, MA, USA
}

Background: We have previously found that $\mathrm{CD} 4{ }^{+} \mathrm{CD} 25^{+}$regulatory $\mathrm{T}$ cells (Tregs) can adoptively transfer tolerance after its induction with costimulatory blockade in a mouse model of murine cardiac allograft transplantation. In these experiments, we tested an hypothesis with three components: (1) the Tregs that transfer tolerance have the capacity for linked suppression, (2) the determinants that stimulate the Tregs are expressed by the indirect pathway, and (3) the donor peptides contributing to these indirect determinants are derived from donor major histocompatibility complex (MHC) antigens (Ags).

Methods: First heart transplants were performed from the indicated donor strain to B10. D2 recipients along with costimulatory blockade treatment (250 $\mu \mathrm{g}$ i.p. injection of MR1 on day 0 and $250 \mu$ g i.p. injection of CTLA-4 Ig on day 2). At least 8 weeks later, a second heart transplant was performed to a new B10.D2 recipient who had been irradiated with 450 cGy. This recipient was given $40 \times 106$ naive B10.D2 spleen cells $+40 \times 106$ B10.D2 spleen cells from the first (tolerant) recipient. We performed three different types of heart transplants using various donors.

Results: (1) Tregs suppress the graft rejection in an Ag-specific manner. (2) Tregs generated in the face of $\mathrm{MHC}$ disparities suppress the rejection of grafts expressing third party $\mathrm{MHC}$ along with tolerant $\mathrm{MHC}$.

Conclusion: The limits of linkage appear to be quantitative and not universally determined by either the indirect pathway or by peptides of donor MHC Ags.

Keywords: costimulation, indirect pathway, MHC class II, tolerance, regulatory T cells

\section{INTRODUCTION}

The physiologically unusual stimulation of T cells by donor antigen-presenting cells (APCs) has been called "direct" recognition, whereas stimulation by self-APCs, presenting peptides of donor origin, has been called "indirect" recognition. Direct recognition has been believed to be the major pathway involved in allograft rejection due to three basic observations, namely, (1) direct stimulation is very strong in a primary allogenic mixed lymphocyte reaction, (2) depletion of donor APCs can

Abbreviations: Ags, antigens; APCs, antigen-presenting cells; MHC, major histocompatibility complex; MST, median survival time; Tregs, regulatory T cells. 
sometimes prolong allograft survival, and (3) donor major histocompatibility complex (MHC) antigens (Ags) are more important than minor Ags in causing graft rejection (1). Matching for MHC Ags achieves better allograft survival. Lechler and Batchelor showed the importance of MHC class II matching compared to MHC class I matching at least in the long-term survival (2). However, there are several remarkable reports of consequences of $\mathrm{T}$ cells responding via the indirect pathway. These reports showed the indirect pathway (a) helps for priming alloreactive CD8 T cells $(3,4),(b)$ is essential for tolerance induction in some models $(5,6)$, and (c) is involved in chronic transplant rejection $(7,8)$. In addition, several papers have shown the importance of an indirect response in allograft rejection $(1,3,9,10)$. Indirect allorecognition contributes not only to acute graft rejection $(2,9)$ but also possibly to the continuing response to the allograft in the long term after transplantation (11). Previously, we tested the role of costimulatory blockade for prolonging allograft survival with using class II-deficient mice when only one or the other pathway of graft rejection was available. We found that to achieve long-term survival after costimulatory blockade requires that the recipient expresses MHC class II molecules (12). This result indicated that indefinite cardiac transplant survival could not be achieved in the absence of an intact indirect pathway. These results are consistent with the fact that at least a component of the regulatory $\mathrm{T}$ cell (Treg) response must involve recognition of peptides of donor Ags presented by recipient $\mathrm{MHC}$ molecules
A

\section{B6 into B10.D2}

(the $1^{\text {st }}$ Transplant)

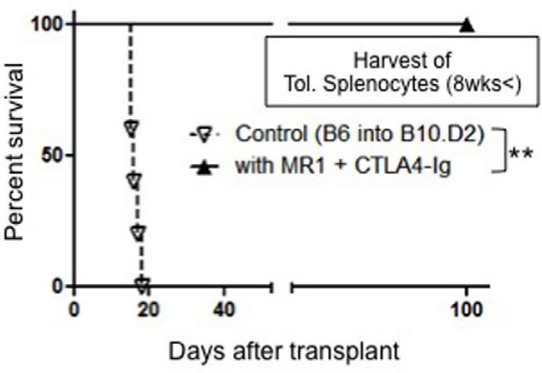

B

B6 into irradiated B10.D2

(the $2^{\text {nd }}$ Transplant)

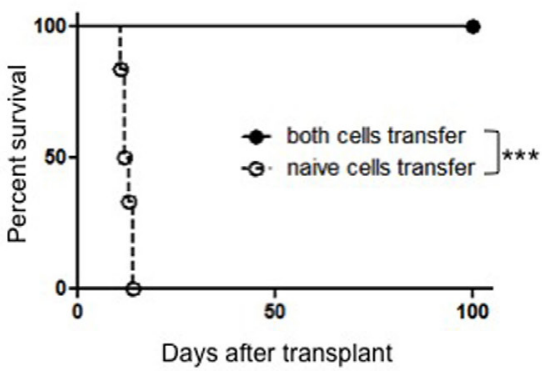

C Allografts expressing different antigens into irradiated B10.D2 (H-2 $\left.{ }^{\mathrm{d} / \mathrm{B} 10}\right)$

(the $3^{\text {rd }}$ Transplant)

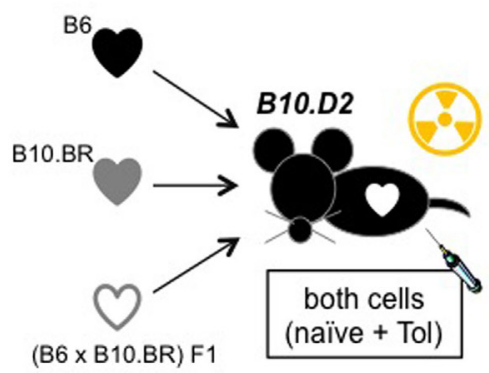

\begin{tabular}{|c|c|c|}
\hline 2nd graft $\quad \mathrm{MHC}$ & H-2 & Minor \\
\hline B6 & b & B6 \\
\hline B10.BR & k & B10 \\
\hline$(\mathrm{B} 6 \times \mathrm{B} 10 . \mathrm{BR}) \mathrm{F} 1$ & $\mathrm{~b} / \mathrm{k}$ & $\mathrm{B} 6 / \mathrm{B} 10$ \\
\hline
\end{tabular}

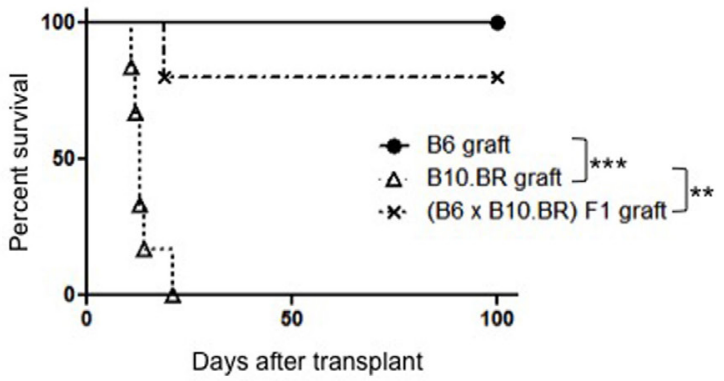

FIGURE 1 | (A) Allograft survival in B10.D2 recipients: (>100 days, $n=5, p=0.0017$ compared to control: 16.2 days, $n=5)$. (B) Adoptive transfer model: naive splenocytes transfer $(n=6)$, both naive and Tol. splenocytes transfer (100 days, $n=6, p=0.0007)$. (C) Linkage model: B6 hearts ( $>100$ days), B10.BR hearts $(\sim 23$ days, $n=6, p=0.0006)(\mathrm{B} 6 \times \mathrm{B} 10 . \mathrm{BR}) \mathrm{F} 1$ ( $>100$ days, $n=4 / 5, p=0.0044)$. 
(13). Authors also mentioned that linked suppression can also be induced through the indirect pathway. However, little work seems to have addressed their direct role in transplantation. Therefore, in the current study, we tested whether the Tregs that transfer tolerance have the capacity for linked suppression.

\section{METHODS AND RESULTS}

First, we made B10.D2 $\left(\mathrm{H}-2^{\mathrm{d}}\right)$ mice tolerant to $\mathrm{B} 6\left(\mathrm{H}-2^{\mathrm{b}}\right)$ with costimulatory blockade [ $250 \mu \mathrm{g}$ intraperitoneal (i.p.) injection of MR1 on day 0 and $250 \mu \mathrm{g}$ i.p. injection of CTLA-4 Ig on day 2] (Figure 1A). At least 8 weeks later, a second heart transplant was performed to a new B10.D2 recipient who had been irradiated with $450 \mathrm{cGy}$. All recipient received intravenous (i.v.) injection of naive $40 \times 10^{6}$ splenocytes $+40 \times 10^{6}$ splenocytes that are taken from the tolerant mice (toleralized splenocytes: Tol.) significantly prolonged graft survival compared to recipient received only naive splenocyte $(12 \pm 1$ days compared to $>100, p<0.001)$ (Figure 1B). After these results, we considered linkage of Tregs. Next, we performed a second transplant from B6 mice to irradiated B10.D2 mice. The second donors express the same $\mathrm{MHC}$ and minor Ags as the first graft or B10.BR heart grafts differ from the first graft in their MHC Ags or $(\mathrm{B} 6 \times \mathrm{B} 10 . \mathrm{BR}) \mathrm{F} 1$ mice, which express both $\mathrm{H}-2^{\mathrm{b}}$ and $\mathrm{H}-2^{\mathrm{k}}$ Ags. After transplant, the mice received i.v. injection of naive and toleralized splenocytes. All B6 hearts survived over 100 days. But $\mathrm{B} 10 . \mathrm{BR}$ hearts expressing third party $\mathrm{MHC}$ were rejected by 23 days (Figure 1C). (B10.BR $\times$ B6) F1 hearts expressing third party MHC with tolerant $\mathrm{MHC}$ showed $80 \%$ survival of over 100 days; however, CAV was observed in some specimen. The institutional subcommittee on research animal care at Massachusetts General Hospital approved all animal experiments.

\section{DISCUSSION}

Linked suppression has often been associated with Tregs, and its mechanisms must be important ones, as tolerance can be extended to whole MHC disparities when applied to cardiac transplantation. Tolerance was extended to third party transplant

\section{REFERENCES}

1. Gould DS, Auchincloss H Jr. Direct and indirect recognition: the role of MHC antigens in graft rejection. Immunol Today (1999) 20:77-82. doi:10.1016/ S0167-5699(98)01394-2

2. Lechler RI, Batchelor JR. Restoration of immunogenicity to passenger celldepleted kidney allografts by the addition of donor strain dendritic cells. J Exp Med (1982) 155:31-41. doi:10.1084/jem.155.1.31

3. Auchincloss H Jr, Sultan H. Antigen processing and presentation in transplantation. Curr Opin Immunol (1996) 8:681-7. doi:10.1016/ S0952-7915(96)80086-0

4. Valujskikh A, Lantz O, Celli S, Matzinger P, Heeger PS. Cross-primed CD8(+) $\mathrm{T}$ cells mediate graft rejection via a distinct effector pathway. Nat Immunol (2002) 3:844-51. doi:10.1038/ni831

5. Kishimoto K, Yuan X, Auchincloss H Jr, Sharpe AH, Mandelbrot DA, Sayegh $\mathrm{MH}$. Mechanism of action of donor-specific transfusion in inducing tolerance: role of donor MHC molecules, donor co-stimulatory molecules, and indirect antigen presentation. J Am Soc Nephrol (2004) 15:2423-8. doi:10.1097/01. ASN.0000137883.20961.2D
Ags, even to MHC-encoded Ags, provided they are expressed on the same graft as the tolerated Ags in some models (14-17). Thus, its mechanism of immunoregulation in transplantation is very important. In addition, understanding interactions between linked suppression and Tregs can potentially be great advantage in the setting of transplantation to propagate the development of specific unresponsiveness once the process has been initiated.

Our preliminary data showed that Tregs suppress the graft rejection in an Ag-specific manner and Tregs generated in the face of MHC disparities suppress the rejection of grafts expressing third party MHC along with tolerant MHC.

\section{CONCLUSION}

The very limited comparison in this experiment will determine whether the patterns of gene expression can reliably distinguish a regulatory population from one that promotes rejection.

\section{AUTHOR CONTRIBUTIONS}

TU, TI, and AY participated in the performance of the research, performed the data collection, performed the statistical analysis, and contributed to the writing of the manuscript; IB, MY, and MM participated in the writing of the manuscript and performed review; and MS and TU designed the study and participated in review. AC participated in review.

\section{ACKNOWLEDGMENTS}

We thank Susan P. Shea and Karla S. Stenger for their invaluable technical assistance and Hugh Auchincloss Jr. for his advice and insight.

\section{FUNDING}

This work was supported by American Heart Association and JSPS KAKENHI. TU is a recipient of the American Heart Association Scientist Development Grant (11SDG5150000) and Grant-in-Aid for Challenging Exploratory Research (15K15479).
6. Lehmann PV, Matesic D, Benichou G, Heeger PS. Induction of T helper 2 immunity to an immunodominant allopeptide. Transplantation (1997) 64:292-6. doi:10.1097/00007890-199707270-00020

7. Hornick PI, Mason PD, Baker RJ, Hernandez-Fuentes M, Frasca L, Lombardi G, et al. Significant frequencies of $\mathrm{T}$ cells with indirect anti-donor specificity in heart graft recipients with chronic rejection. Circulation (2000) 101:2405-10. doi:10.1161/01.CIR.101.20.2405

8. Yamada A, Laufer TM, Gerth AJ, Chase CM, Colvin RB, Russell PS, et al. Further analysis of the T-cell subsets and pathways of murine cardiac allograft rejection. Am J Transplant (2003) 3:23-7. doi:10.1034/ j.1600-6143.2003.30105.x

9. Auchincloss H Jr, Lee R, Shea S, Markowitz JS, Grusby MJ, Glimcher LH. The role of "indirect" recognition in initiating rejection of skin grafts from major histocompatibility complex class II-deficient mice. Proc Natl Acad Sci U S A (1993) 90:3373-7. doi:10.1073/pnas.90.8.3373

10. Sayegh $\mathrm{MH}$, Carpenter CB. Role of indirect allorecognition in allograft rejection. Int Rev Immunol (1996) 13:221-9. doi:10.3109/08830189609061749

11. Wood KJ, Sakaguchi S. Regulatory T cells in transplantation tolerance. Nat Rev Immunol (2003) 3:199-210. doi:10.1038/nri1027 
12. Yamada A, Chandraker A, Laufer TM, Gerth AJ, Sayegh MH, Auchincloss H Jr. Recipient MHC class II expression is required to achieve long-term survival of murine cardiac allografts after costimulatory blockade. J Immunol (2001) 167:5522-6. doi:10.4049/jimmunol.167.10.5522

13. Wise MP, Bemelman F, Cobbold SP, Waldmann H. Linked suppression of skin graft rejection can operate through indirect recognition. J Immunol (1998) 161:5813-6.

14. Adeegbe D, Levy RB, Malek TR. Allogeneic T regulatory cell-mediated transplantation tolerance in adoptive therapy depends on dominant peripheral suppression and central tolerance. Blood (2010) 115:1932-40. doi:10.1182/ blood-2009-08-238584

15. Chen Z, Morgan R, Berger CS, Sandberg AA. Application of fluorescence in situ hybridization in hematological disorders. Cancer Genet Cytogenet (1992) 63:62-9. doi:10.1016/0165-4608(92)90066-H

16. Davies JD, Leong LY, Mellor A, Cobbold SP, Waldmann H. T cell suppression in transplantation tolerance through linked recognition. J Immunol (1996) 156:3602-7.
17. Wong W, Morris PJ, Wood KJ. Pretransplant administration of a single donor class I major histocompatibility complex molecule is sufficient for the indefinite survival of fully allogeneic cardiac allografts: evidence for linked epitope suppression. Transplantation (1997) 63:1490-4. doi:10.1097/00007890-199705270-00020

Conflict of Interest Statement: The authors declare that the research was conducted in the absence of any commercial or financial relationships that could be construed as a potential conflict of interest.

Copyright (๑) 2016 Ito, Yamada, Batal, Yeung, McGrath, Sayegh, Chandraker and Ueno. This is an open-access article distributed under the terms of the Creative Commons Attribution License (CC BY). The use, distribution or reproduction in other forums is permitted, provided the original author(s) or licensor are credited and that the original publication in this journal is cited, in accordance with accepted academic practice. No use, distribution or reproduction is permitted which does not comply with these terms. 